\title{
Handedness and Dexterity Evaluation System Using Haptic Virtual Reality Technology
}

\author{
Masanao Koeda, Mako Matsuyama, \\ Munetaka Sugihashi and Tsuneo Yoshikawa \\ Ritsumeikan University \\ Japan
}

\section{Introduction}

It is considered that the ratio of right-handed to left-handed persons is 9 to 1 approximately, and most products are created for right-handed persons. Right-handed persons are mostly unaware of the inconvenience, however, it is a deep problem for left-handed persons.

Quantitative evaluation of handedness of people will be useful in various situations. For example, handedness is an important factor in designing tools and devices that are to be handled by people using their hands. It will also be useful for knowing the degree of recovery of a person in rehabilitation stage suffering from injury or disease.

A well-known method for evaluating handedness of a person is LQ (laterality quotient)method (Oldfield,R.C.1971) which is based on the answers to ten questions such as which hand 1 uses for writing letters. (Matsuda et al.,2003) propose to evaluate handedness based on the results of tests of tapping, peg-board, and picking up beans using discriminant function analysis.

There are many researches trying to find functional differences between dominant and non dominant hands. (Fujiwara et al.,2003) use a digital trace method for studying the difference of upper limb coordination between dominant and non-dominant hands. (Wu et al.,1996) examine the difference between the behaviors during the operation of touch panel by the dominant and non-dominant hands. (Bagesteiro et al.,2002) investigate interlimb differences in coordination through analysis of inverse dynamics and electromyography recorded during the performance of reaching movements. These studies assume that subjects in their experiments can be divided into 2 groups: right-handed persons and left-handed persons. However, there are many persons who are neither 100\% right-handed nor 100\% left-handed persons. In order to properly take these persons into consideration in various studies related to handedness of people, we need to consider the quantitative degree of handedness of each subject. One possible direction of future research will be to consider the quantitative degree of handedness of each subject.

We have also proposed a method for evaluating quantitatively the handedness and dexterity (Yoshikawa et al.,2007). The evaluation method is based on a performance of some test tasks in the virtual world that are constructed using haptic virtual reality technology. Haptic virtual reality is a technology which makes it possible for us to see and touch a virtual environment composed by a computer through a haptic display device. Various researches have been done so far in this field (Burdea,G.C.,1996). We have proposed a methodology for displaying the 
dynamics of virtual objects (Yoshikawa et al.,1995), and developed a system for observing human skill by using a virtual task space (Yoshikawa et al.,2000). The merits of virtual test tasks over real tasks in evaluating the handedness are that it is easier to provide a large variety of tasks, to change the values of parameters of these tasks, and to obtain detailed position and force data for evaluation. In this method, 3 test tasks were prepared: accurate positioning task, accurate force control task, and skillful manipulation task. Performance data for these test tasks taken from a group of subjects are analyzed using the factor analysis. Since the obtained factor scores for the right and left hands of each subject can be regarded as the skillfulness of the right and left hand, it was proposed to define the degree of handedness and dexterity of the subject based on the difference and average of these factor scores respectively. The results of the judgment of handedness from this method for the ten subjects were consistent with that from the conventional LQ method. However, these tests had some problems:

- The desired position was not indicated clearly in the position control test.

- The indication method of desired force was not easily viewable in the force control test.

- The grasping position was no specified clearly in the manipulation test, therefore some subjects were confused.

In this study, the problems of the tests of the previous method were modified, and we describe the following points:

1. A new test task was added to measure combined dexterity of position and force control of fingertips.

2. The learning effect of each test was investigated.

3. Three test tasks in the real space were conducted.

By using this system, experiments to measure handedness and dexterity were conducted to 12 subjects, and the performance of the new system is discussed.

\section{Outline of handedness and dexterity evaluation system}

An experimental system shown in Fig. 1 has been developed for measuring the dexterity of a finger from the following 4 viewpoints:

1. Position control

2. Force control

3. Manipulation of objects

\section{Position-force combined control}

The system consists of 2 force display devices (PHANToM OMNI), a display, and a computer for constructing a virtual task world. The specifications of the computer and the force display device are shown in Table 1,2. The test task applications which is described in detail in the next section are all needed to be controlled using one's finger. Therefore, the original attachment which is shown in Fig. 2 was installed instead of the standard stylus. 


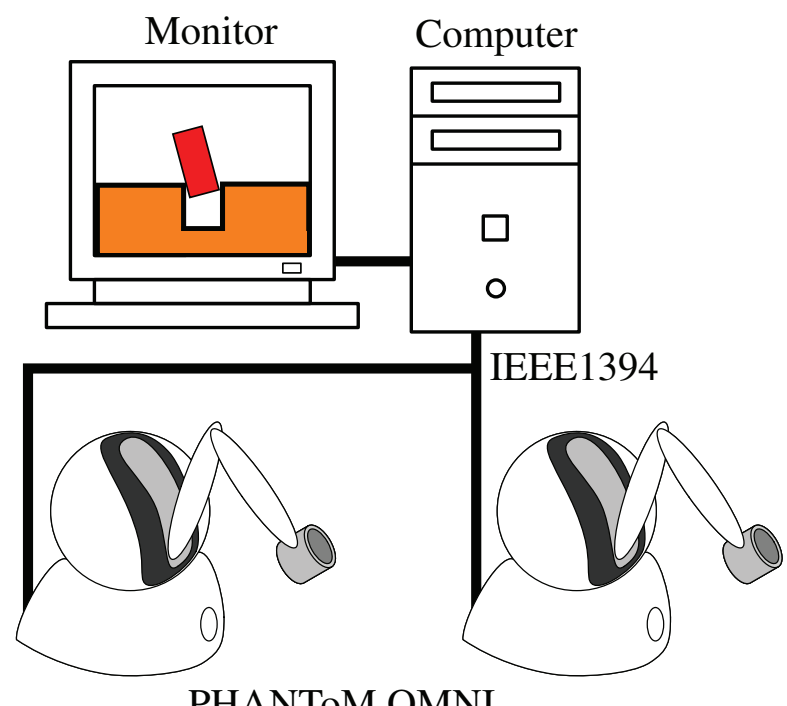

Fig. 1. System configuration

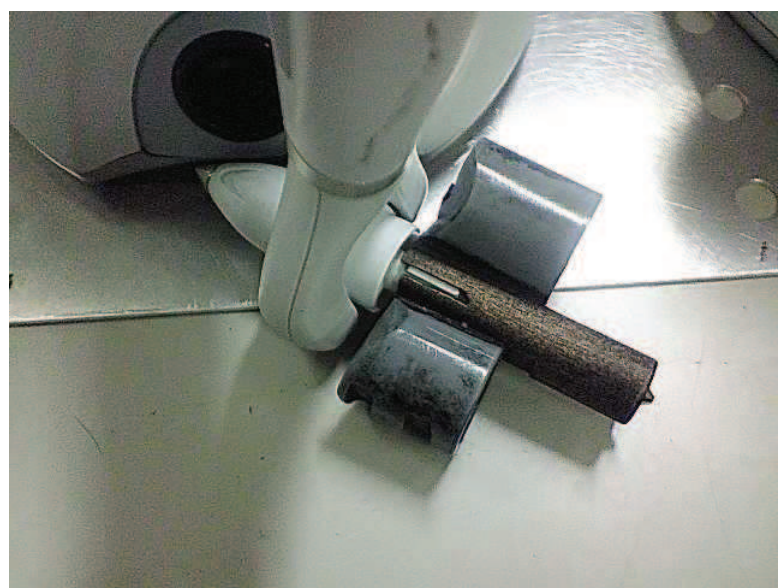

Fig. 2. Original attachment for our test tasks

\section{Test tasks in virtual space}

\subsection{Position control test}

This test is intended to measure the dexterity in positioning a fingertip accurately. The subject is asked to follow the desired point on the screen which moves along a circle with the constant velocity by using his/her index finger. The desired point turns around the circle 5 times taking 6 seconds for each turn. Fig.3-(a) shows the image on the monitor screen, and Fig.3-(b) shows the handling style of the attachment. In a right hand test, the desired point rotates in clockwise direction along the circle and in a left hand test, the desired point rotates in counterclockwise direction along the circle. 


\begin{tabular}{|l|l|}
\hline OS & Microsoft Windows XP Professional \\
\hline CPU & Intel Xeon $51402.33[\mathrm{GHz}]$ \\
\hline Memory & $2[\mathrm{~GB}]$ \\
\hline GPU & NVIDIA Quadro FX 550 \\
\hline Bus Type & PCI Express $\times 16$ \\
\hline
\end{tabular}

Table 1. Specifications of computer

\begin{tabular}{|l|l|}
\hline Force Feedback Workspace & $160 \mathrm{~W} \times 120 \mathrm{H} \times 70 \mathrm{D}[\mathrm{mm}]$ \\
\hline Position Resolution & $0.055[\mathrm{~mm}]$ \\
\hline Maximum Exertable Force & $3.3[\mathrm{~N}]$ \\
\hline Continuous Exertable Force & $0.88[\mathrm{~N}]$ \\
\hline Stiffness & $\begin{array}{l}\mathrm{X} \text { axis } 1.26[\mathrm{~N} / \mathrm{mm}] \\
\text { Y axis } 2.31[\mathrm{~N} / \mathrm{mm}] \\
\mathrm{Z} \text { axis } 1.02[\mathrm{~N} / \mathrm{mm}]\end{array}$ \\
\hline Force Feedback & $\mathrm{X}, \mathrm{y}, \mathrm{z}$ \\
\hline Interface & $\mathrm{IEEE}-1394$ FireWire \\
\hline
\end{tabular}

Table 2. Specifications of PHANToM OMNI

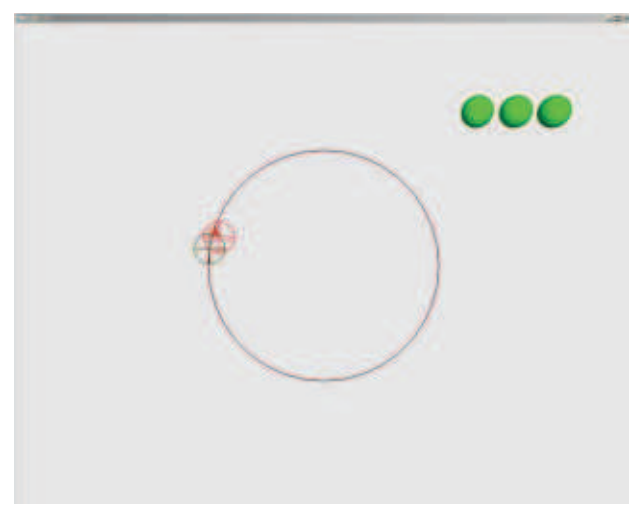

(a) Image on the monitor

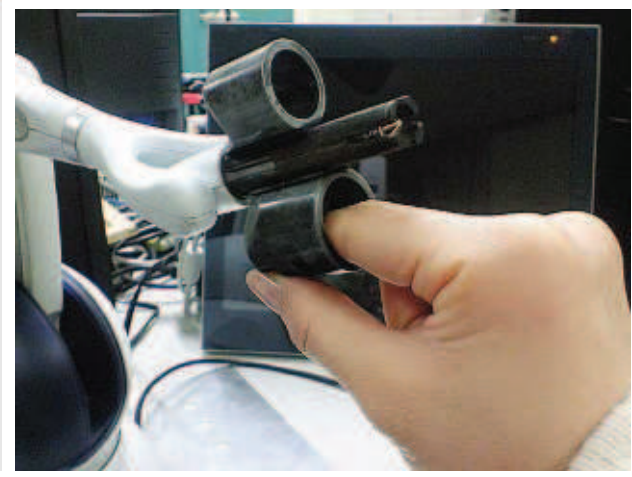

(b) Handling

Fig. 3. Position control test

The average of the tracking error during the 5 turns from the 2nd to the 4 th turn is taken as the measure of performance of this task. As is shown in Fig.4, the tracking error $e_{p}(t)$ at time $t$ is given by

$$
\begin{aligned}
\boldsymbol{P}(t) & =\left[\begin{array}{ll}
x(t) & y(t)
\end{array}\right]^{T} \\
\boldsymbol{P}_{d}(t) & =\left[\begin{array}{ll}
x_{d}(t) y_{d}(t)
\end{array}\right]^{T}=\left[\begin{array}{ll}
r \cos \left(\omega_{p} t\right) & r \sin \left(\omega_{p} t\right)
\end{array}\right]^{T} \\
e_{p}(t) & =\sqrt{\left\|\boldsymbol{P}(t)-\boldsymbol{P}_{d}(t)\right\|}
\end{aligned}
$$

where $\boldsymbol{P}(t)$ is the position vector of the fingertip on the virtual plane shown by a red circle $\boldsymbol{P}_{d}(t)$ is the desired position vector of the fingertip shown by a green circle, and $\omega_{p}$ is the 


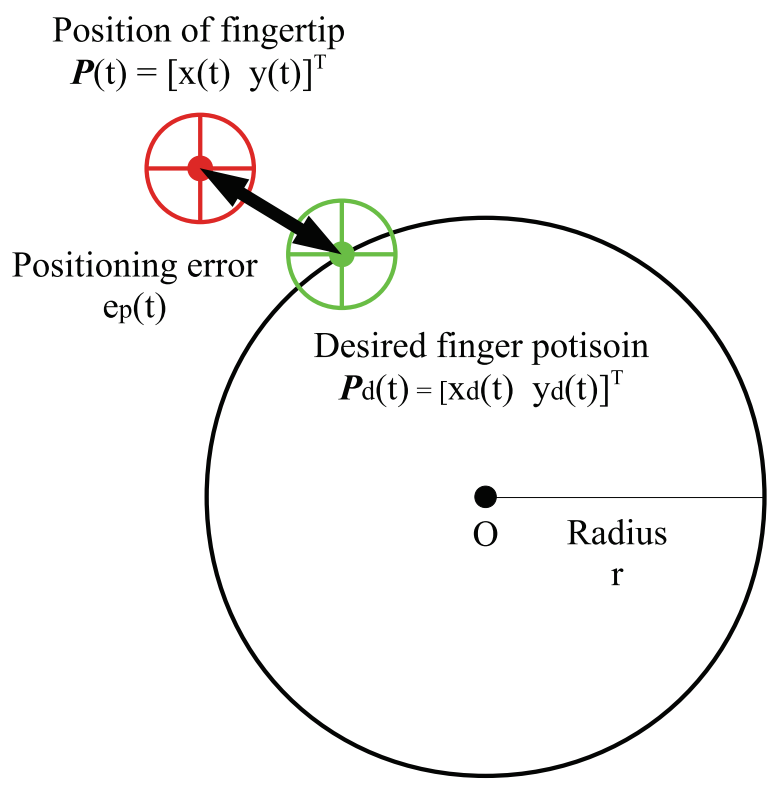

Fig. 4. Positioning error

rotational velocity of $\boldsymbol{P}_{d}(t)\left(=-2 \pi / 6\left[\mathrm{~s}^{-1}\right]\right.$ in a right hand test, $=2 \pi / 6\left[\mathrm{~s}^{-1}\right]$ in a left hand test). The measure of performance $E_{p}$ is given by the average magnitude of tracking error, that is,

$$
\begin{aligned}
& E_{p}^{n}=\frac{\int_{0}^{T} e_{p}(t) d t}{T} \\
& E_{p}=\frac{\sum_{n=1}^{N} E_{p}^{n}}{N}
\end{aligned}
$$

where $E_{p}^{n}$ is the performance of the $n$th trial, $N$ is the number of trial(=3), $T$ is the total time (=30 [s]). The smaller the value $E_{p}$ is, the more dexterous the subject is regarded in position control.

\subsection{Force control test}

This test is intended to measure the dexterity in exerting desired force on a virtual object by fingertips accurately. The subject is asked to pinch a green virtual object in the screen by using index and thumb finger. The both sides of the object are concaved to be pinched easily. Fig.5-(a) shows the image on the monitor screen and Fig.5-(b) shows the handling style of the attachment in this test. When the subject pinches the box, he/she can feel the reaction force through the force display device. The reaction force is calculated by using a spring-damper model of the surface of box. The subject can also watch the relative magnitude of the exerted force $\boldsymbol{F}(t)$ and the desired force $F_{d}(t)$ by the gauge which is placed in right side of the monitor. The task continues 30 seconds and the data is obtained during 6 through 24 seconds skipping the first and last 6 second.

The average of the force control error during the 18 seconds is taken as the measure of performance of this task. As is shown in Fig. 6, exerted force and desired force are displayed 


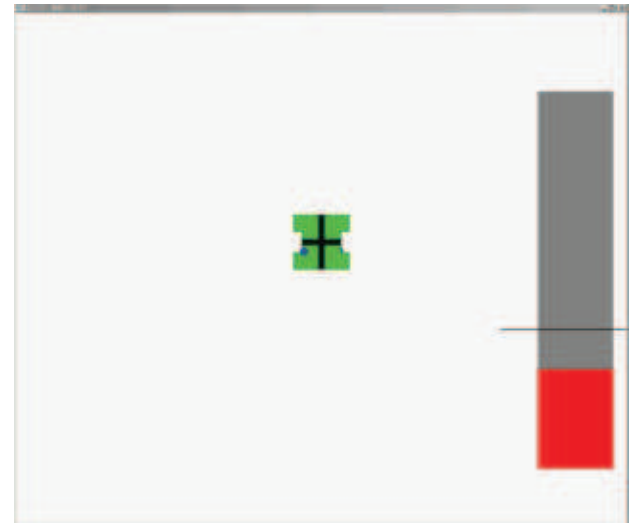

(a) Image on the monitor

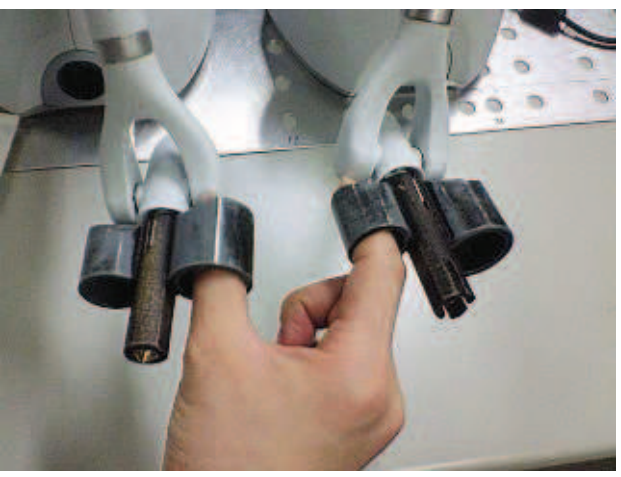

(b) Handling

Fig. 5. Force control test

and the force error is shown clearly to the subject than the previous force test. The force control error $e_{f}(t)$ at time $t$ is given by

$$
\begin{aligned}
F(t) & =\frac{\left\|\boldsymbol{F}_{l}(t)\right\|+\left\|\boldsymbol{F}_{r}(t)\right\|}{2} \\
F_{d}(t) & =1.5+\sin \left(\omega_{f} t\right) \\
e_{f}(t) & =\left|F(t)-F_{d}(t)\right|
\end{aligned}
$$

where $\boldsymbol{F}_{l}(t)$ and $\boldsymbol{F}_{r}(t)$ is the force vector of left and right finger, $F_{d}(t)$ is the desired force, $\omega_{f}$ is the frequency of the desired force $\left(=2 \pi / 3\left[\mathrm{~s}^{-1}\right]\right)$. The measure of performance $E_{f}$ is given by

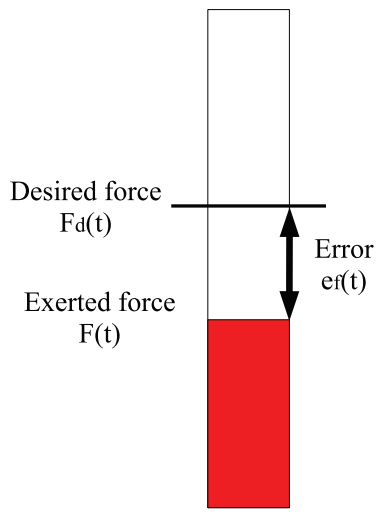

Fig. 6. Force error

$$
\begin{aligned}
& E_{f}^{n}=\frac{\int_{0}^{T} e_{f}(t) d t}{T} \\
& E_{f}=\frac{\sum_{n=1}^{N} E_{f}^{n}}{N}
\end{aligned}
$$


where $E_{f}^{n}$ is the performance of the $n$th trial, $N$ is the number of trial(=3), $T$ is the total time $(=18[\mathrm{~s}])$. The smaller the value $E_{f}$ is, the more dexterous the subject is regarded in force control.

Here, we describe the method for generating the contact force between a finger and a virtual object in this test. To generate virtual space and force to the force display device (PHANToM OMNI), we used Haptic Library API (HLAPI). HLAPI is distributed from SensAble Technologies, Inc. (SensAble Technologies,Inc.) and it provides a lot of useful functions to develop applications for PHANToM OMNI. By using this library, it is easy to measure the position and orientation of the device and control the force in virtual space in real time. The control period of the force display device using this library is $1[\mathrm{~ms}]$.

Now, let us suppose the situation that is illustrated in Fig. 7, where $\boldsymbol{P}_{m}(t)$ and $\boldsymbol{P}_{c}(t)$ indicate the measured and current position of a finger in a virtual space respectively.

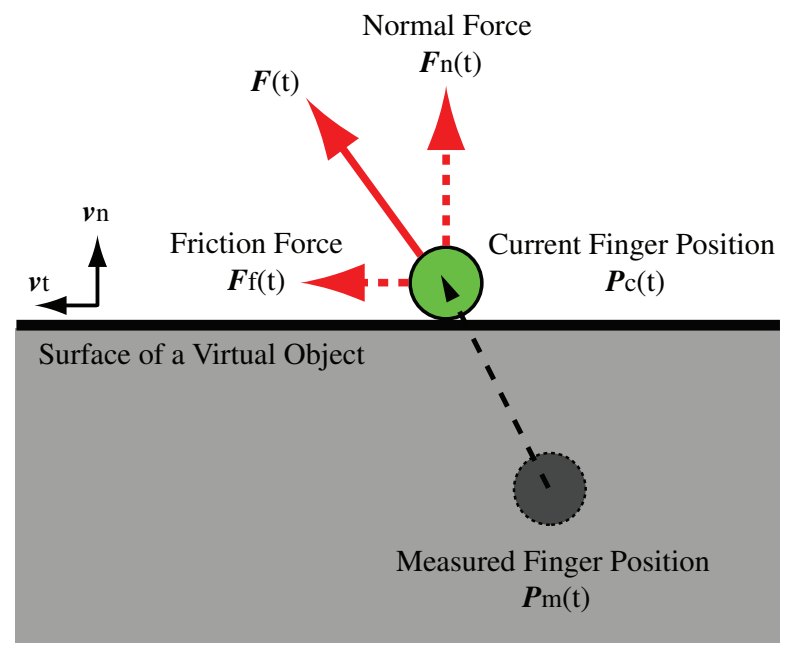

Fig. 7. Virtual object, finger position, and exerted force

Surface of a Virtual Object

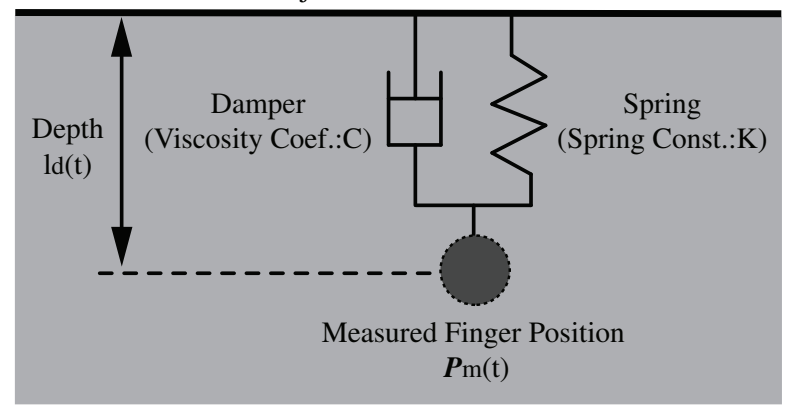

Fig. 8. Spring-damper model 


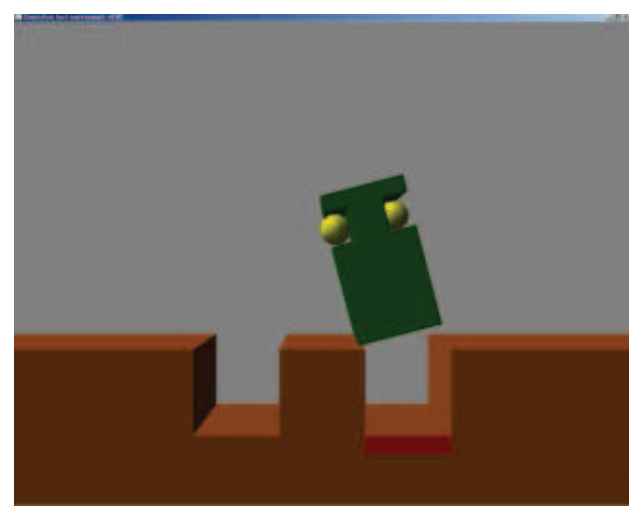

(a) Image on the monitor

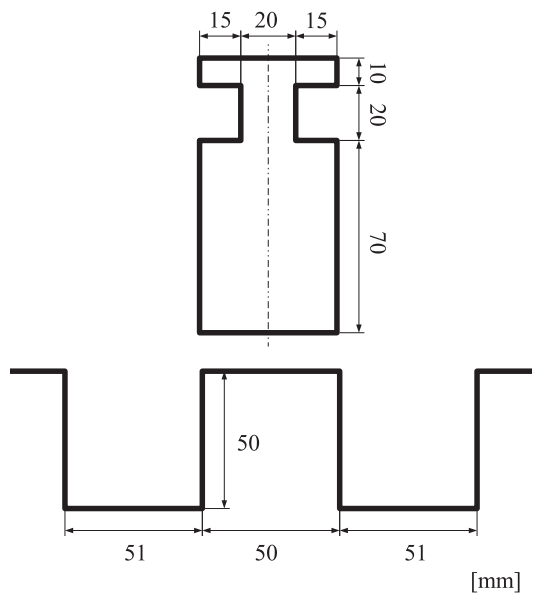

(b) Size of peg and holes

Fig. 9. Manipulation test

To display the force from the virtual object, spring-damper model is estimated shown in Fig. 8, and normal force vector $\boldsymbol{F}_{n}(t)$ and friction force vector $\boldsymbol{F}_{f}(t)$ is defined as following equations:

$$
\begin{aligned}
& \boldsymbol{F}_{n}(t)=\left\{K l_{d}(t)+C l_{d}(t)\right\} \boldsymbol{v}_{n} \\
& \boldsymbol{F}_{f}(t)=\mu\left\|\boldsymbol{F}_{n}(t)\right\| \boldsymbol{v}_{t}
\end{aligned}
$$

where $l_{d}(t)$ is the depth of measured finger position, $\left.l_{d} \dot{(} t\right)$ is the velocity of finger motion, $\boldsymbol{v}_{n}$ is the unit normal vector of the surface, $\boldsymbol{v}_{t}$ is the unit tangent vector of the surface, $K$ is the spring constant, $C$ is the viscosity coefficient, and $\mu$ is the friction coefficient.

\subsection{Manipulation test}

This test is intended to measure the dexterity of a subject in manipulating objects by his/her hand. The subject is asked to insert a peg into a hole in virtual world, which is constructed by using a dynamics simulator: Open Dynamics Engine (Smith,R.,2000). The interaction forces among the fingertips, peg, and hole are calculated based on the intrusion distance among them following the approach described in (Yoshikawa et al.,2000).

The gravitational acceleration is assumed to be $9800\left[\mathrm{~mm} / \mathrm{s}^{2}\right]$. The task is specified in the 2-dimensional space by constraining the motion of peg in a plane parallel to the monitor screen. The subject is asked to pick up a peg of $50[\mathrm{~mm}]$ wide, $20[\mathrm{~mm}]$ wide at handling position, $100[\mathrm{~mm}]$ long, and weighing $75[\mathrm{~g}]$, by his/her thumb and index finger. The size of hole is $50[\mathrm{~mm}]$ deep and $51[\mathrm{~mm}]$ wide. Fig.9-(a) shows the image on the monitor screen and Fig.9-(b) illustrates the detail of the size of the peg and holes. The handling style is same as the force test shown in Fig.5-(b). To specify the grasping position and manipulate easily, the both sides of the peg are concaved.

The subject is asked to insert the peg into the next hole by 4 times. (see Fig.10). The time $E_{m}^{n}$ needed to perform this insertion task is taken as the measure of performance.

$$
E_{m}=\frac{\sum_{n=1}^{N} E_{m}^{n}}{N}
$$


where $N$ is the number of trial(=3). The smaller the value $E_{m}$ is, the more dexterous the subject is regarded in manipulation control.

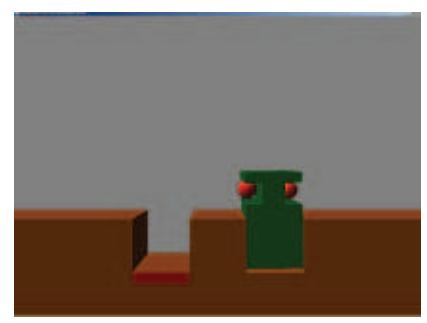

(a)

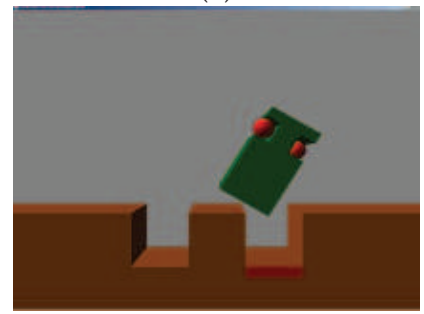

(d)

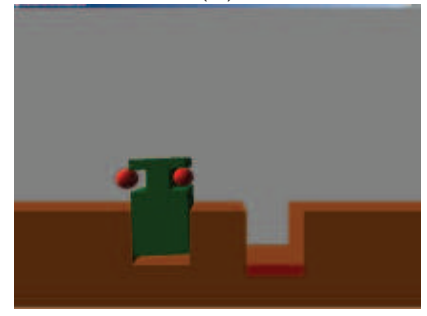

(g)

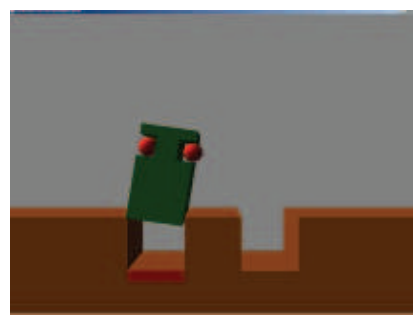

(b)

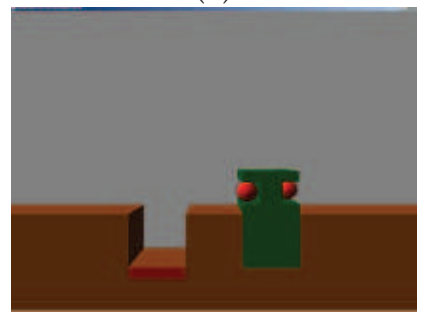

(e)

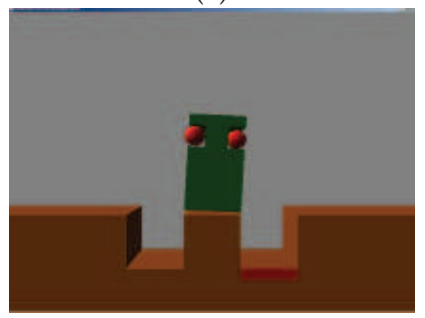

(h)

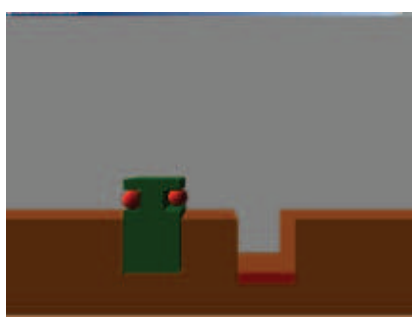

(c)

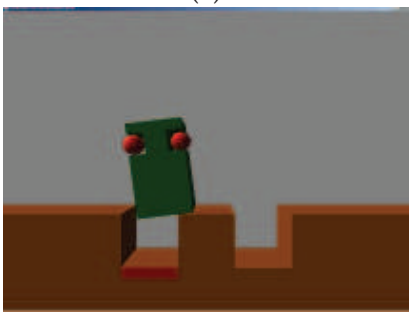

(f)

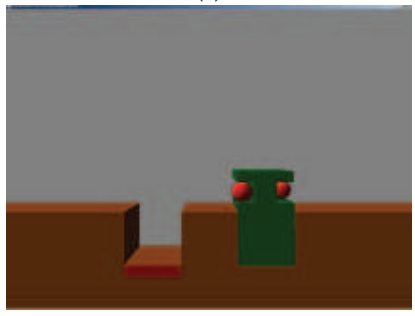

(i)

Fig. 10. Snapshots in manipulation test task

\subsection{Position-Force combined test}

This test is intended to measure the dexterity of a subject in simultaneous control of position and force by his/her fingertips. Fig.11 shows the image on the monitor screen of this test, and the handling style is same as the force test shown in Fig.5-(b). This test was constructed by combining the 2 tests previously described: position control test and force control test. The subject is asked to pinch a green virtual object in the screen with the constant force by using index and thumb finger, and the subject is also asked to follow the marker which indicates desired finger point. The marker moves along a circle with the constant velocity. The desired point turns around the circle 5 times taking 6 seconds for each turn. The average of the tracking error during the 5 turns from the 2 nd to the 4 th turn is taken as the measure of performance of this task. The gauge which is placed in center of the monitor indicates the exerted force and the desired force. The handling style is same as the force test shown in Fig.5-(b).

The measure of performance $E_{c p}^{n}$ and $E_{c f}^{n}$ are given by the same method of the position control test and force control test as previously described. Note that desired force $F_{d}(t)$ is constant 
value $(=0.93[\mathrm{~N}])$ in this test.

$$
\begin{aligned}
& E_{c p}=\frac{\sum_{n=1}^{N} E_{c p}^{n}}{N} \\
& E_{c f}=\frac{\sum_{n=1}^{N} E_{c f}^{n}}{N}
\end{aligned}
$$

where $E_{c p}^{n}$ and $E_{c f}^{n}$ are the performance of the $n$th trial, $N$ is the number of trial(=3).

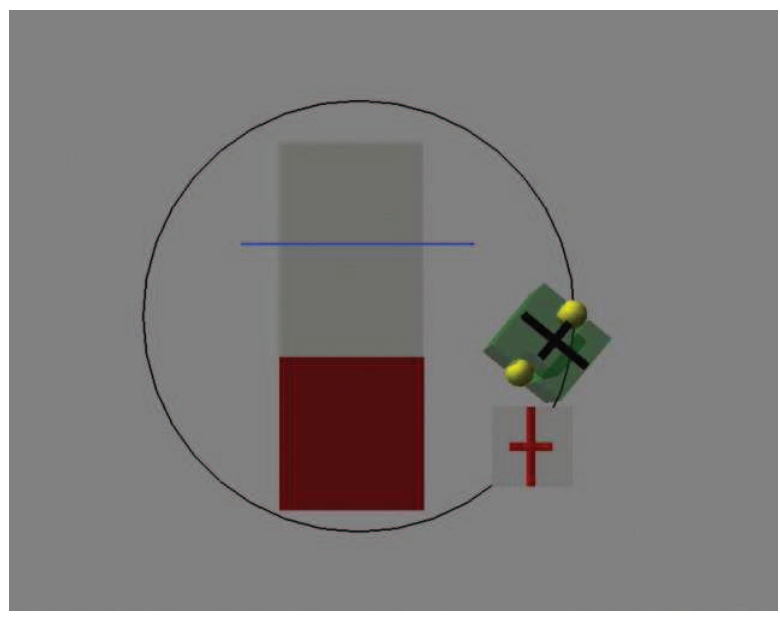

Fig. 11. Image on the monitor of Position-force combined test

\section{Experimental results}

\subsection{LQ test}

10 male and 2 female subjects of age 21-24 have taken the LQ tests. The questionnaire form of the test is shown in Table. 3. According to the conventional LQ test, 9 subjects (Subject A-J) were right-handed, 1 subject (Subject L) was left-handed, and subject K was ambidexterity (see Table 4).

\subsection{Test tasks in virtual space}

First of all, we investigated learning effect of the proposed test tasks. This investigation was conducted to subject M. Fig.12 shows learning curves of each test. It seems that all tests except manipulation test are not affected by learning so much. However, manipulation test is needed a little training for stable data acquisition.

Then, 1 minute training was imposed before all tests, and tests were repeated 3 times for the right and left hands of each subject.

Their averages were regarded as the measured performance data denoted as

$$
\left\{E_{i h p}, E_{i h f}, E_{i h m}, E_{i h c p}, E_{i h c f}\right\}
$$

where subscript $i$ means subject $i=A, B, \cdots, L$, subscript $h$ means left hand $(h=l)$ or right hand $(h=r)$, and subscripts $p, f, m, c p$, and $c f$ mean the position control, the force control, the manipulation, position control in the combined test, and force control in the combined test respectively. Table 5,6 and Fig.13 show the measured data. 


\begin{tabular}{|c|c|c|c|c|}
\hline No. & Question & Left Hand & Right Hand & Both \\
\hline 1 & $\begin{array}{c}\text { Which hand do you use } \\
\text { when writing? }\end{array}$ & & & \\
\hline 2 & $\begin{array}{c}\text { Which hand do you use } \\
\text { when using chopsticks? }\end{array}$ & & & \\
\hline 3 & $\begin{array}{c}\text { Which hand do you use } \\
\text { when drawing a picture? }\end{array}$ & & & \\
\hline 4 & $\begin{array}{c}\text { Which hand do you use } \\
\text { when throwing a ball? }\end{array}$ & & & \\
\hline 5 & $\begin{array}{c}\text { Which hand do you use } \\
\text { when using scissors? }\end{array}$ & & & \\
\hline 6 & $\begin{array}{c}\text { Which hand do you use } \\
\text { when brushing teeth? }\end{array}$ & & & \\
\hline 7 & $\begin{array}{c}\text { Which hand do you use } \\
\text { when using a spoon? }\end{array}$ & & & \\
\hline 8 & $\begin{array}{c}\text { Which hand do you use } \\
\text { when sweeping by a short broom? }\end{array}$ & & & \\
\hline 9 & $\begin{array}{c}\text { Which hand do you use } \\
\text { when lighting a match? }\end{array}$ & & & \\
\hline 10 & $\begin{array}{c}\text { Which hand do you use } \\
\text { when unscrewing a bottle cap? }\end{array}$ & & & \\
\hline
\end{tabular}

Table 3. LQ questionnaire form

\begin{tabular}{|c|c|c|c|c|c|c|c|c|c|c|r|}
\hline & \multicolumn{7}{|c|}{ Question No. } & \\
Subject & $\mathbf{1}$ & $\mathbf{2}$ & $\mathbf{3}$ & $\mathbf{4}$ & $\mathbf{5}$ & $\mathbf{6}$ & $\mathbf{7}$ & $\mathbf{8}$ & $\mathbf{9}$ & $\mathbf{1 0}$ & LQ Value \\
\hline $\mathrm{A}$ & $\mathrm{R}$ & $\mathrm{R}$ & $\mathrm{R}$ & $\mathrm{R}$ & $\mathrm{R}$ & $\mathrm{R}$ & $\mathrm{R}$ & $\mathrm{R}$ & $\mathrm{R}$ & $\mathrm{R}$ & $\mathbf{1 0 0}$ \\
\hline $\mathrm{B}$ & $\mathrm{R}$ & $\mathrm{R}$ & $\mathrm{R}$ & $\mathrm{R}$ & $\mathrm{R}$ & $\mathrm{R}$ & $\mathrm{R}$ & $\mathrm{R}$ & $\mathrm{R}$ & $\mathrm{R}$ & $\mathbf{1 0 0}$ \\
\hline $\mathrm{C}$ & $\mathrm{R}$ & $\mathrm{R}$ & $\mathrm{R}$ & $\mathrm{R}$ & $\mathrm{R}$ & $\mathrm{R}$ & $\mathrm{R}$ & $\mathrm{R}$ & $\mathrm{R}$ & $\mathrm{R}$ & $\mathbf{1 0 0}$ \\
\hline $\mathrm{D}$ & $\mathrm{R}$ & $\mathrm{R}$ & $\mathrm{R}$ & $\mathrm{R}$ & $\mathrm{R}$ & $\mathrm{R}$ & $\mathrm{R}$ & $\mathrm{R}$ & $\mathrm{R}$ & $\mathrm{R}$ & $\mathbf{1 0 0}$ \\
\hline $\mathrm{E}$ & $\mathrm{R}$ & $\mathrm{R}$ & $\mathrm{R}$ & $\mathrm{R}$ & $\mathrm{R}$ & $\mathrm{R}$ & $\mathrm{R}$ & $\mathrm{R}$ & $\mathrm{R}$ & $\mathrm{R}$ & $\mathbf{1 0 0}$ \\
\hline $\mathrm{F}$ & $\mathrm{R}$ & $\mathrm{R}$ & $\mathrm{R}$ & $\mathrm{R}$ & $\mathrm{R}$ & $\mathrm{R}$ & $\mathrm{R}$ & $\mathrm{R}$ & $\mathrm{R}$ & $\mathrm{R}$ & $\mathbf{1 0 0}$ \\
\hline $\mathrm{G}$ & $\mathrm{R}$ & $\mathrm{R}$ & $\mathrm{R}$ & $\mathrm{R}$ & $\mathrm{R}$ & $\mathrm{R}$ & $\mathrm{R}$ & $\mathrm{R}$ & $\mathrm{R}$ & $\mathrm{R}$ & $\mathbf{1 0 0}$ \\
\hline $\mathrm{H}$ & $\mathrm{R}$ & $\mathrm{R}$ & $\mathrm{R}$ & $\mathrm{R}$ & $\mathrm{R}$ & $\mathrm{R}$ & $\mathrm{R}$ & $\mathrm{R}$ & $\mathrm{R}$ & $\mathrm{R}$ & $\mathbf{1 0 0}$ \\
\hline $\mathrm{I}$ & $\mathrm{R}$ & $\mathrm{R}$ & $\mathrm{R}$ & $\mathrm{R}$ & $\mathrm{R}$ & $\mathrm{R}$ & $\mathrm{R}$ & $\mathrm{R}$ & $\mathrm{R}$ & $\mathrm{R}$ & $\mathbf{1 0 0}$ \\
\hline $\mathrm{J}$ & $\mathrm{R}$ & $\mathrm{R}$ & $\mathrm{R}$ & $\mathrm{R}$ & $\mathrm{R}$ & $\mathrm{R}$ & $\mathrm{R}$ & $\mathrm{R}$ & $\mathrm{R}$ & $\mathrm{L}$ & $\mathbf{8 0}$ \\
\hline $\mathrm{K}$ & $\mathrm{R}$ & $\mathrm{R}$ & $\mathrm{R}$ & $\mathrm{L}$ & $\mathrm{L}$ & $\mathrm{R}$ & $\mathrm{R}$ & $\mathrm{B}$ & $\mathrm{R}$ & $\mathrm{B}$ & $\mathbf{4 0}$ \\
\hline $\mathrm{L}$ & $\mathrm{L}$ & $\mathrm{L}$ & $\mathrm{L}$ & $\mathrm{L}$ & $\mathrm{L}$ & $\mathrm{L}$ & $\mathrm{L}$ & $\mathrm{L}$ & $\mathrm{L}$ & $\mathrm{L}$ & $\mathbf{- 1 0 0}$ \\
\hline
\end{tabular}

Table 4. Results of LQ value (R: Right Hand, L: Left Hand, B:Both)

\section{Test tasks in real space}

To investigate the relativity between virtual space and real space, we conducted 3 tests in real space: Picking up beans, moving pegs, and hitting counter test. Since this research is under investigation, overview of the experiments and experimental results are just shown in this paper. 


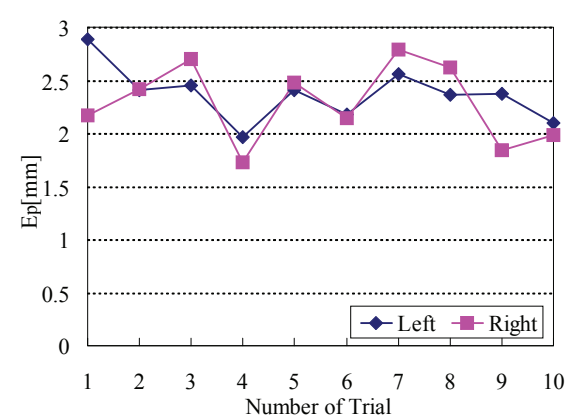

(a) Position control test

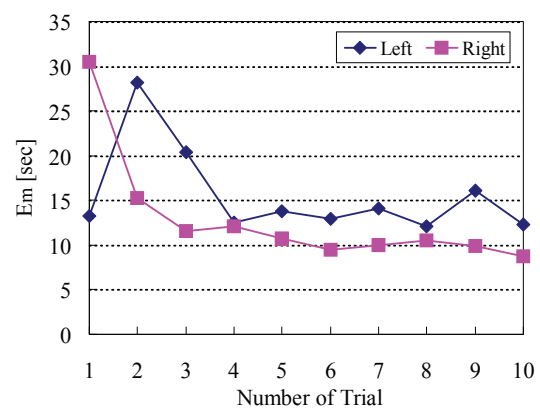

(c) Manipulation test

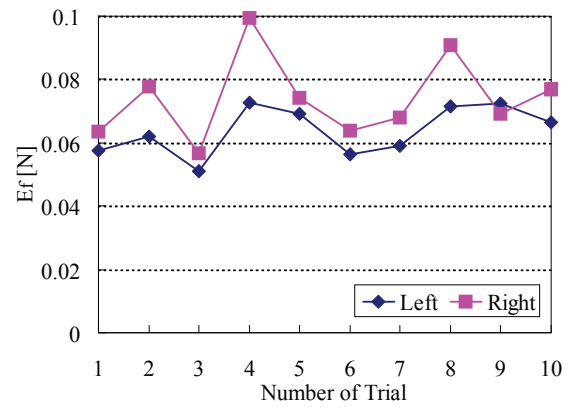

(b) Force control test

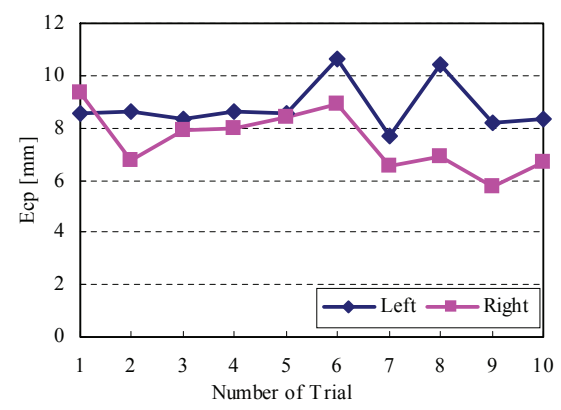

(d) Combined test (Position)

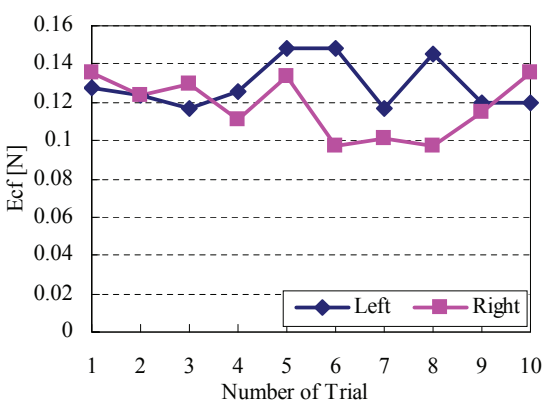

(e) Combined test (Force)

Fig. 12. Learning curves of subject $M$ for the virtual space tests

\subsection{Picking up beans test}

The subject is asked to pick up a bean (soy bean, about $10[\mathrm{~mm}]$ in diameter) and move it to the next dish by using chopsticks, repeating 5 times for each hand. The size of dish is $100[\mathrm{~mm}]$ in diameter, and the distance between two dishes is $50[\mathrm{~mm}]$. The dishes are fixed to the table by the double-stick tape. The experimental setup of this test and the experimental result are shown is shown in Fig.14-(a), Table 7, and Fig. 15-(a). 


\begin{tabular}{|c|c|c|c|c|c|c|}
\hline \multirow{2}{*}{ Subject } & \multicolumn{2}{|c|}{ Position test [mm] } & \multicolumn{2}{|c|}{ Force test [N] } & \multicolumn{3}{|c|}{ Manipulation test [s] } \\
\cline { 2 - 7 } & L.H. & R.H. & L.H. & R.H. & L.H. & R.H. \\
& $E_{\text {ilp }}$ & $E_{\text {irp }}$ & $E_{\text {ilf }}$ & $E_{\text {irf }}$ & $E_{\text {ilm }}$ & $E_{\text {irm }}$ \\
\hline $\mathrm{A}$ & 2.805 & 2.210 & 0.1463 & 0.0918 & 7.686 & 5.626 \\
\hline $\mathrm{B}$ & 2.503 & 1.673 & 0.1060 & 0.0702 & 5.848 & 5.757 \\
\hline $\mathrm{C}$ & 2.810 & 1.801 & 0.0747 & 0.0783 & 10.013 & 9.035 \\
\hline $\mathrm{D}$ & 2.137 & 1.710 & 0.0848 & 0.0709 & 9.880 & 8.314 \\
\hline $\mathrm{E}$ & 2.774 & 2.170 & 0.0763 & 0.0931 & 7.803 & 6.881 \\
\hline $\mathrm{F}$ & 2.717 & 2.571 & 0.1209 & 0.0910 & 8.330 & 9.358 \\
\hline $\mathrm{G}$ & 2.946 & 2.854 & 0.1122 & 0.1263 & 13.523 & 11.190 \\
\hline $\mathrm{H}$ & 1.614 & 1.551 & 0.0638 & 0.0770 & 8.852 & 8.630 \\
\hline $\mathrm{I}$ & 2.619 & 2.462 & 0.1039 & 0.0813 & 8.508 & 9.613 \\
\hline $\mathrm{J}$ & 2.301 & 2.137 & 0.1014 & 0.0907 & 6.747 & 5.248 \\
\hline $\mathrm{K}$ & 1.696 & 1.850 & 0.0765 & 0.0789 & 7.880 & 8.730 \\
\hline $\mathrm{L}$ & 2.141 & 2.177 & 0.1066 & 0.0965 & 7.092 & 7.930 \\
\hline
\end{tabular}

Table 5. Experimental results of position, force and manipulation test in virtual space (L.H.: Left Hand, R.H.:Right Hand)

\begin{tabular}{|c|c|c|c|c|}
\hline \multirow{2}{*}{ Subject } & \multicolumn{3}{|c|}{ Position [mm] } & \multicolumn{2}{c|}{ Force [N] } \\
\cline { 2 - 5 } & $\begin{array}{c}\text { L.H. } \\
E_{\text {ilcp }}\end{array}$ & $\begin{array}{c}\text { R.H. } \\
E_{\text {ircp }}\end{array}$ & $\begin{array}{c}\text { L.H. } \\
E_{\text {ilcf }}\end{array}$ & $\begin{array}{c}\text { R.H. } \\
E_{\text {ircf }}\end{array}$ \\
\hline A & 8.519 & 8.108 & 0.130 & 0.125 \\
\hline B & 11.208 & 6.833 & 0.286 & 0.095 \\
\hline C & 6.194 & 6.193 & 0.219 & 0.134 \\
\hline D & 8.056 & 7.175 & 0.236 & 0.200 \\
\hline E & 5.521 & 4.798 & 0.255 & 0.149 \\
\hline F & 8.072 & 8.125 & 0.191 & 0.144 \\
\hline G & 13.398 & 12.293 & 0.156 & 0.115 \\
\hline H & 5.424 & 4.811 & 0.271 & 0.148 \\
\hline I & 8.953 & 8.530 & 0.322 & 0.222 \\
\hline J & 6.346 & 5.517 & 0.134 & 0.104 \\
\hline K & 7.576 & 5.586 & 0.271 & 0.153 \\
\hline L & 6.020 & 6.334 & 0.175 & 0.152 \\
\hline
\end{tabular}

Table 6. Experimental results of the combined test in virtual space (L.H.: Left Hand, R.H.:Right Hand)

\subsection{Moving pegs test}

The subject is asked to pick up a small peg and move it to the hole below, repeating 20 times for each hand. The size of peg is about $6[\mathrm{~mm}]$ in diameter, $10[\mathrm{~mm}]$ deep, and the distance between holes is $12[\mathrm{~mm}]$ approximately. The board with holes is fixed to the table by the double-stick tape. The experimental setup of this test and the experimental result are shown in Fig.14-(b), Table 7, and Fig. 15-(b). 


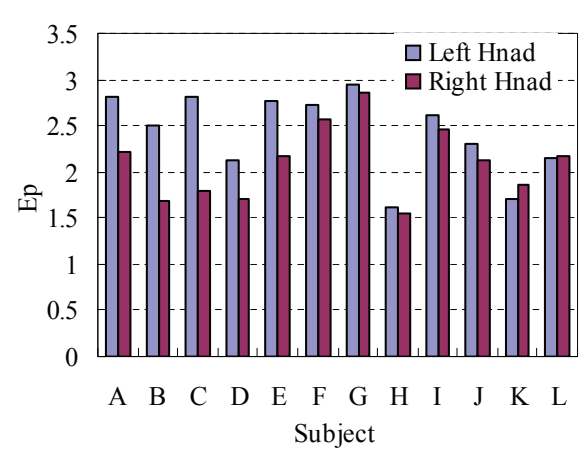

(a) Position control test

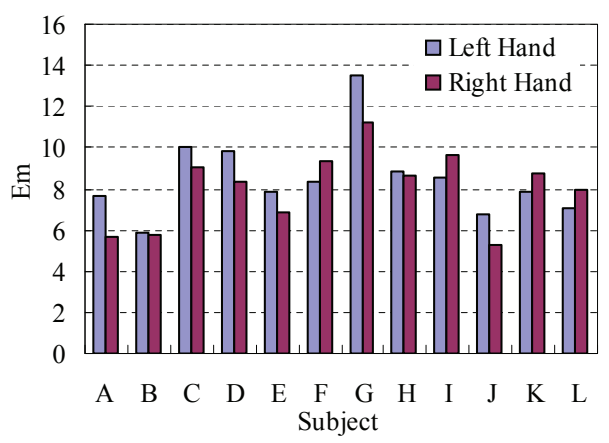

(c) Manipulation test

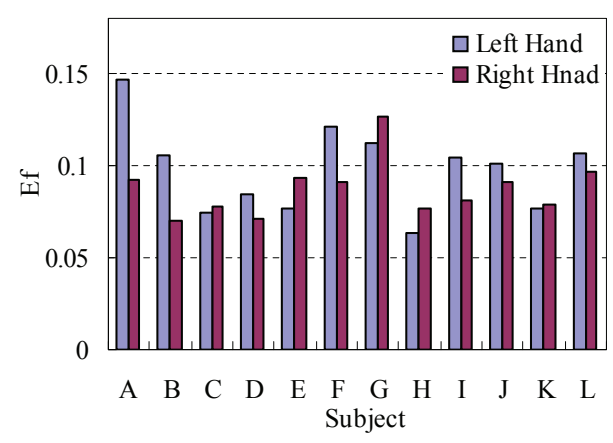

(b) Force control test

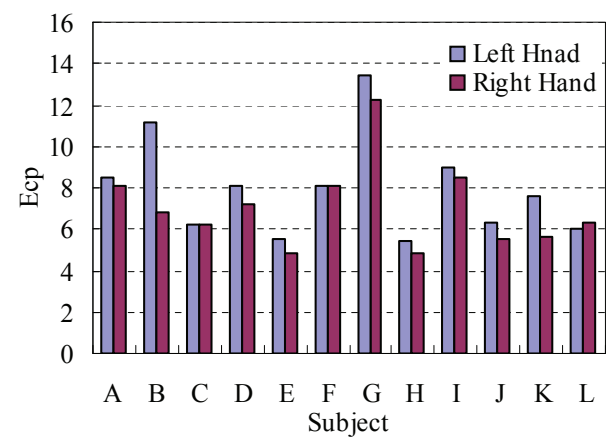

(d) Combined test (position)

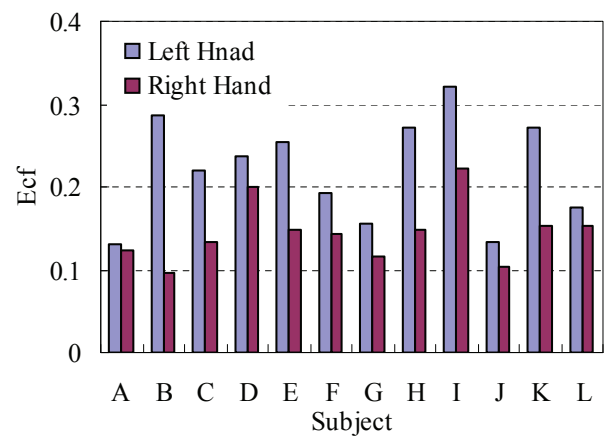

(f) Combined test (force)

Fig. 13. Results of the virtual space tests

\subsection{Hitting counter test}

The subject is asked to hit counters alternately, repeating 100 times for each hand. The counter is fixed to the table by the double-stick tape. The experimental setup of this test and the experimental result are shown in Fig.14-(c), Table 7, and Fig. 15-(c). 


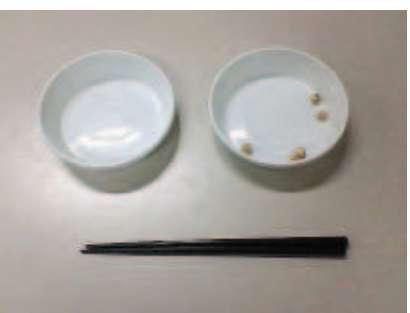

(a) Picking up beans

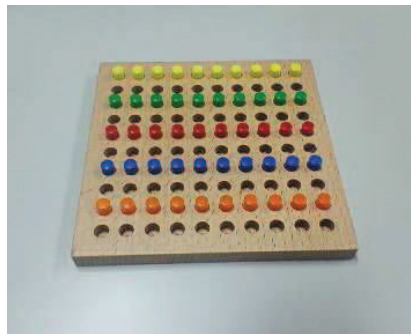

(b) Moving pegs

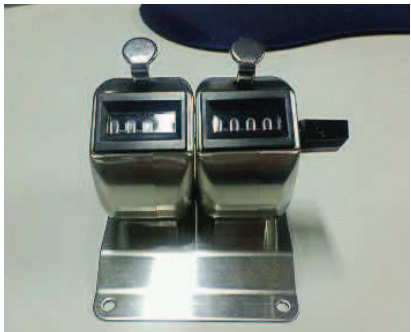

(c) Hitting counter

Fig. 14. Experimental setups of real space test

\begin{tabular}{|c|c|c|c|c|c|c|}
\hline \multirow{2}{*}{ Subject } & \multicolumn{2}{|c|}{ Picking up beans [s] } & \multicolumn{2}{|c|}{ Moving pegs [s] } & \multicolumn{2}{|c|}{ Hitting counter [s] } \\
\hline & L.H. & R.H. & L.H. & R.H. & L.H. & R.H. \\
\hline A & 32.15 & 12.08 & 16.62 & 15.19 & 26.81 & 20.75 \\
\hline B & 85.40 & 14.96 & 18.93 & 13.00 & 25.20 & 19.41 \\
\hline $\mathrm{C}$ & 100.79 & 17.97 & 16.74 & 16.30 & 23.02 & 20.50 \\
\hline $\mathrm{D}$ & 37.81 & 14.65 & 16.17 & 13.33 & 21.49 & 14.97 \\
\hline $\mathrm{E}$ & 23.92 & 22.48 & 16.71 & 15.63 & 32.28 & 22.72 \\
\hline $\mathrm{F}$ & \begin{tabular}{|l|}
71.42 \\
\end{tabular} & 27.54 & 15.82 & 13.27 & 27.28 & 15.96 \\
\hline G & 28.06 & 16.59 & 17.10 & 14.68 & 24.65 & 21.85 \\
\hline $\mathrm{H}$ & 39.12 & 17.85 & 20.96 & 21.72 & 21.29 & 20.04 \\
\hline I & \begin{tabular}{|l|}
51.49 \\
\end{tabular} & 26.14 & 29.81 & 19.16 & 28.86 & 23.77 \\
\hline $\mathrm{J}$ & 24.96 & 12.28 & 17.28 & 15.37 & 29.55 & 21.78 \\
\hline K & 59.14 & 48.25 & 22.36 & 21.96 & 19.08 & 18.18 \\
\hline $\mathrm{L}$ & 17.21 & 26.68 & 16.45 & 22.24 & 21.69 & 22.33 \\
\hline
\end{tabular}

Table 7. Experimental results of real space tests (L.H.: Left Hand, R.H.:Right Hand)

\section{Definition and evaluation of handedness and dexterity}

We have proposed a quantitative definition of the handedness and dexterity based on the factor analysis in (Yoshikawa et al.,2007). Based on this method, we adapt and apply it for the new test tasks.

To analyze the obtained data by the factor analysis, we first standardize the measured performances for each test as follows. The standardized value $z$ of datum $E$ is given by

$$
z_{i h t}=\frac{E_{i h t}-\bar{E}_{t}}{v_{t}}, \quad t=p, f, m, c p, c f
$$

where $\bar{E}_{t}$ and $v_{t}$ are, respectively, the average and the standard variation of the data $\left\{E_{i h t}\right\}$ of each test $t$.

Let the standardized performance data for hand $h$ of subject $i$ for the test $t$ be $z_{\text {iht }}$. Then from the basic formula of the factor analysis we adopt the one-factor model given by

$$
z_{i h t}=a_{t} d_{i h}+e_{i h t}
$$

where $d_{i h}$ is the factor score, $a_{t}$ are the factor loading coefficients for the 4 tests, and $e_{i h t}$ are the independent errors. 


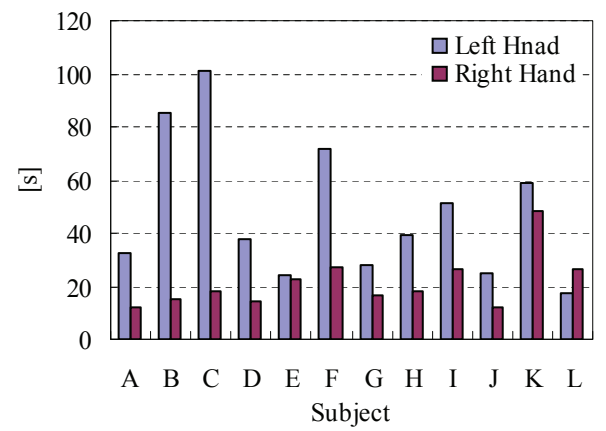

(a) Picking up beans

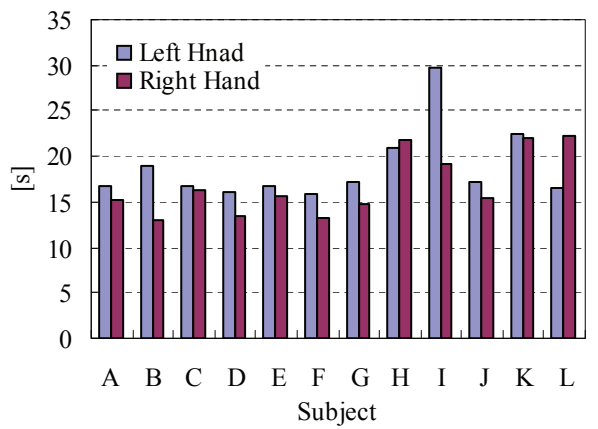

(b) Moving pegs

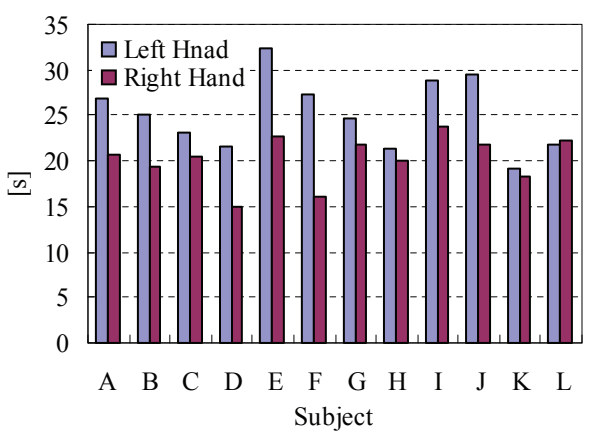

(c) Hitting counter

Fig. 15. Experimental results in real space test

In order to calculate the factor score, we first obtain the values of factor loadings. Let the factor loading matrix $\boldsymbol{A}$ be

$$
\boldsymbol{A}=\left[\begin{array}{lllll}
a_{p} & a_{f} & a_{m} & a_{c p} & a_{c f}
\end{array}\right]^{T}
$$

then the relation between $\boldsymbol{A}$ and the correlation matrix $\boldsymbol{R}$ is given by

$$
\boldsymbol{R}=\boldsymbol{A} \boldsymbol{A}^{T}+\boldsymbol{R}_{e}
$$

where $\boldsymbol{R}_{e}$ is the diagonal covariance matrix of the independent errors. The correlation matrix $\boldsymbol{R}$ is also calculated from the performance data Table 5, 6,

$$
\boldsymbol{R}=\left[\begin{array}{rrrrr}
1 & 0.670 & 0.360 & 0.590 & 0.078 \\
0.670 & 1 & 0.100 & 0.565 & -0.212 \\
0.360 & 0.100 & 1 & 0.485 & 0.114 \\
0.590 & 0.565 & 0.485 & 1 & 0.097 \\
0.078 & -0.212 & 0.114 & 0.097 & 1
\end{array}\right]
$$

Using the Principal Factor Method, factor loading matrix $\boldsymbol{A}$ satisfying (19) is given by

$$
\boldsymbol{A}=\left[\begin{array}{lllll}
-0.839 & -0.690 & -0.418 & -0.804 & -0.022
\end{array}\right]^{T}
$$


Now we can obtain the factor score $d_{i h}$ based on the relation

$$
d_{i h}=\left[\begin{array}{lllll}
z_{i h p} & z_{i h f} & z_{i h m} & z_{i h c p} & z_{i h c f}
\end{array}\right] \boldsymbol{R}^{-1} \boldsymbol{A}
$$

Note that, although matrix $-\boldsymbol{A}$ can also be a solution of (19), the above solution with negative components was intentionally chosen. This way, we can obtain the factor score such that the larger the factor score is, the more dexterous the subject is.

Based on the above considerations, we define the dexterity $d_{i}$ and handedness $h_{i}$ of a subject using the factor score of his/her right hand $d_{i r}$ and left hand $d_{i l}$ :

$$
\begin{aligned}
& d_{i}=\frac{d_{i r}+d_{i l}}{2} \\
& h_{i}=\frac{d_{i r}-d_{i l}}{2}
\end{aligned}
$$

\begin{tabular}{|c|c|c|c|c|c|}
\hline \multirow{2}{*}{ Subject } & \multicolumn{2}{|c|}{ Factor score } & \multirow{2}{*}{$\begin{array}{c}\text { Handedness } \\
h_{i}\end{array}$} & \multirow{2}{*}{$\begin{array}{c}\text { Dexterity } \\
d_{i}\end{array}$} & \multirow{2}{*}{ LQ } \\
\hline & $d_{i l}$ & $d_{i r}$ & & & \\
\hline $\mathrm{A}$ & -1.104 & -0.104 & 0.500 & -0.604 & 100 \\
\hline B & -1.024 & 0.862 & 0.943 & -0.081 & 100 \\
\hline C & -0.308 & 0.829 & .568 & 0.261 & 100 \\
\hline $\mathrm{D}$ & 0.093 & 0.815 & 0.361 & 0.454 & 100 \\
\hline $\mathrm{E}$ & -0.095 & 0.640 & 0.367 & 0.273 & 100 \\
\hline $\mathrm{F}$ & -0.769 & -0.537 & 0.116 & -0.653 & 100 \\
\hline G & -2.162 & -1.898 & 0.132 & -2.030 & 100 \\
\hline $\mathrm{H}$ & 1.373 & 1.433 & 0.030 & 1.403 & 100 \\
\hline I & -0.670 & -0.394 & 0.138 & -0.532 & 100 \\
\hline $\mathrm{J}$ & 0.121 & 0.510 & 0.195 & 0.316 & 80 \\
\hline K & 0.786 & 0.910 & 0.062 & 0.848 & 40 \\
\hline $\mathrm{L}$ & 0.393 & 0.300 & -0.047 & 0.347 & -100 \\
\hline
\end{tabular}

\section{Discussion}

The factor scores of the right and left hands of each subject are given in Table 8 and in Fig.16.

Table 8. Evaluation results of dexterity and handedness

The dexterity is shown in Fig.17. The handedness and the LQ value of each subject are shown in Fig.18. From the LQ value, subject L was only regarded left-handedness, and our method conducted the same result. Though, the LQ values of subject A-L were in the same value 100, and the results of the handedness $h_{i}$ were different widely. It can be said that our method can indicate the handedness in detail than the LQ method. The values of the handedness $h_{i}$ of Subject F, G and $\mathrm{H}$ make a little difference. However, the values of the dexterity $d_{i}$ are much different because of the difference of the factor scores $d_{i l}, d_{i r}$. Thus, it requires attention when they have similar handedness value.

Fig.19 shows the result of the factor score, handedness and dexterity, which are analyzed by using the three test method in the previous paper: position, force, and manipulation test, excepting the combined test results (this will be call Three-Test Method hereafter). Subject $\mathrm{K}$ was determined as left-handedness based on the Three-Test Method. By contrast, from the LQ value, he uses right hand mainly in daily life, so he can be regarded as right-handedness in this time. From an interview after the experiment, he talked that he had been used the left 


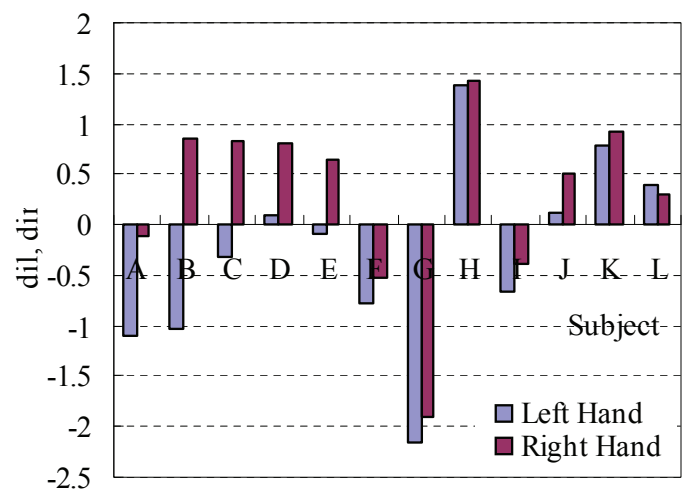

Fig. 16. Factor scores

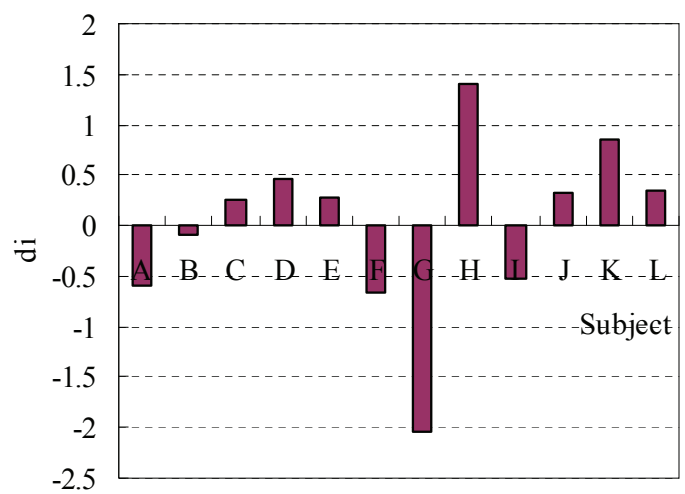

Fig. 17. Dexterity

hand mainly in childhood. The new method indicates weak right-handedness to subject $\mathrm{K}$. It may be that the new method can analyze the handedness more precisely.

\section{Conclusion}

In this paper, a new handedness and dexterity evaluation system was presented. In this system, for accuracy evaluation of handedness and dexterity, 4 test tasks in virtual space are constructed: position control, force control, manipulation and position-force combined control. By using the evaluation method based on the factor analysis which was applied from the previous work (Yoshikawa et al.,2007), experiments to evaluate the handedness and dexterity were conducted to 12 subjects. As a result, the judgment of handedness from our method was consistent with the LQ method, and the new method may analyze the handedness more precisely. Additionally, for the future investigation, 3 tests in real space were conducted and shown the experimental results. 


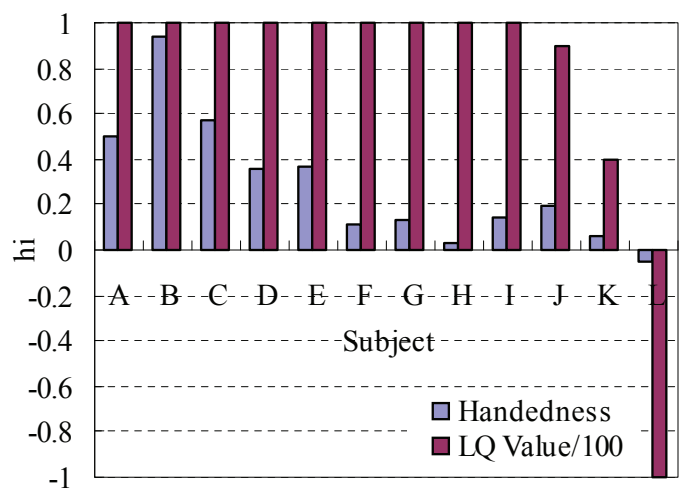

Fig. 18. Handedness

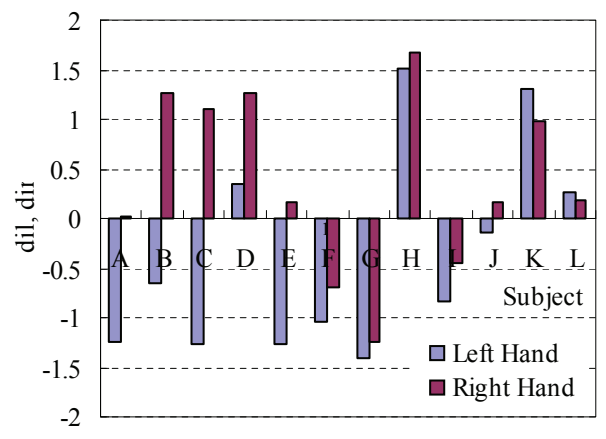

(a) Factor scores

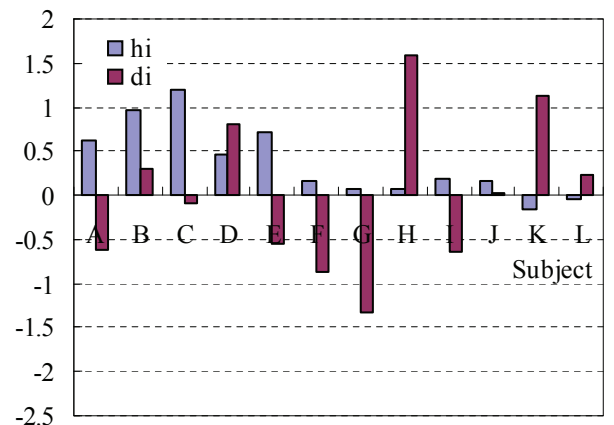

(b) Handedness and Dexterity

Fig. 19. Evaluation by Three-Test Method

For future works, much more subjects should be investigated by our evaluation system, especially, left-handedness and ambidexterity persons. The investigation between virtual and real space is also needed.

\section{References}

[Bagesteiro et al.,2002] Bagesteiro, L.B. and Sainburg, R.L., Handedness: Dominant Arm Advantages in Control of Limb Dynamics, Journal of Neurophysiology, Vol. 88, No. 5, p. 2408-2421, (2002)

[Burdea,G.C.,1996] Burdea, G.C.,A Wiley-Interscience Publication, John Wiley \& Sons, Inc., Force and Touch Feedback for Virtual Reality, (1996)

[Fujiwara et al.,2003] Fujiwara, N. and Kushida, N. and Murakami, T. and Fujimoto, S.,Upper Limb Coordination Differs Among Ages and Between Dominant and Non-dominant Hands Utilizing Digital Trace Test, Journal of health sciences, Hiroshima University,Vol. 2,No. 2, p. 22-28, (2003) 
[Matsuda et al.,2003] Matsuda, I. and Yamaguchi, M. and Yoshida, K.,Quantitative Discrimination of Handedness - Preliminary Study Using Discriminant Analysis Approach -, Sagyouryouhou (Journal published by Japanese Association of Occupational Therapists,Vol. 5, p. 40-41 (in Japanese), (2003)

[Oldfield,R.C.1971] Oldfield, R.C., The Assessment and Analysis of Handedness: The Edinburgh Inventory, Neuropsychologia,Vol. 9, No. 1,p. 97-113, (1971)

[Wu et al.,1996] Wu, J. and Morimoto, K. and Kurokawa, T., A Comparison between Effect of Handedness and Non-handedness on Touch Screen Operation, Transactions of Human Interface Society, Vol. 11, No. 4, p. 441-446 (in Japanese), (1996)

[Yoshikawa et al.,1995] Yoshikawa, T. and Yokokohji, Y. and Matsumoto, T. and Zheng, X-Z., Display of Feel for the Manipulation of Dynamic Virtual Objects, Journal of Dynamic Systems, Measurement, and Control, Vol. 117, No. 4, p. 554-558, (1995)

[Yoshikawa et al.,2000] Yoshikawa, T. and Yoshimoto, K., Haptic Simulation of Assembly Operation in Virtual Environment, Proceedings of the ASME, Dynamic Systems and Control Division-2000, p. 1191-1198, (2000)

[Smith,R.,2000] Smith, R., Open Dynamics Engine, http://www . ode.org/, (2000)

[SensAble Technologies,Inc.] SensAble Technologies, Inc., http://www.sensable.com/, (1993)

[Yoshikawa et al.,2007] Yoshikawa, T. and Koeda, M. and Sugihashi, M.A Quantitative Evaluation Method of Handedness Using Haptic Virtual Reality Technology, Proceedings of the 16th IEEE International Symposium on Robot \& Human Interactive Communication, p. 298-303, (2007) 


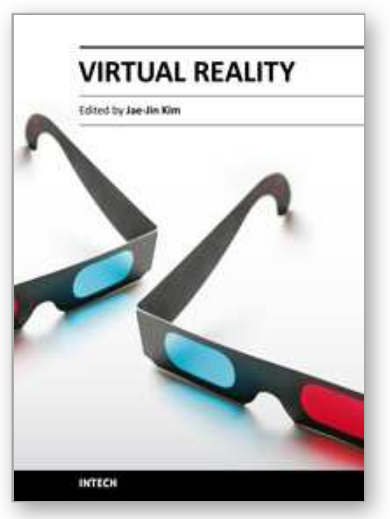

\author{
Virtual Reality \\ Edited by Prof. Jae-Jin Kim
}

ISBN 978-953-307-518-1

Hard cover, 684 pages

Publisher InTech

Published online 08, December, 2010

Published in print edition December, 2010

Technological advancement in graphics and other human motion tracking hardware has promoted pushing "virtual reality" closer to "reality" and thus usage of virtual reality has been extended to various fields. The most typical fields for the application of virtual reality are medicine and engineering. The reviews in this book describe the latest virtual reality-related knowledge in these two fields such as: advanced human-computer interaction and virtual reality technologies, evaluation tools for cognition and behavior, medical and surgical treatment, neuroscience and neuro-rehabilitation, assistant tools for overcoming mental illnesses, educational and industrial uses In addition, the considerations for virtual worlds in human society are discussed. This book will serve as a state-of-the-art resource for researchers who are interested in developing a beneficial technology for human society.

\title{
How to reference
}

In order to correctly reference this scholarly work, feel free to copy and paste the following:

Masanao Koeda, Mako Matsuyama, Munetaka Sugihashi and Tsuneo Yoshikawa (2010). Handedness and Dexterity Evaluation System Using Haptic Virtual Reality Technology, Virtual Reality, Prof. Jae-Jin Kim (Ed.), ISBN: 978-953-307-518-1, InTech, Available from: http://www.intechopen.com/books/virtualreality/handedness-and-dexterity-evaluation-system-using-haptic-virtual-reality-technology

\section{INTECH}

open science | open minds

\author{
InTech Europe \\ University Campus STeP Ri \\ Slavka Krautzeka 83/A \\ 51000 Rijeka, Croatia \\ Phone: +385 (51) 770447 \\ Fax: +385 (51) 686166 \\ www.intechopen.com
}

\author{
InTech China \\ Unit 405, Office Block, Hotel Equatorial Shanghai \\ No.65, Yan An Road (West), Shanghai, 200040, China \\ 中国上海市延安西路65号上海国际贵都大饭店办公楼 405 单元 \\ Phone: +86-21-62489820 \\ Fax: +86-21-62489821
}


(C) 2011 The Author(s). Licensee IntechOpen. This chapter is distributed under the terms of the Creative Commons Attribution-NonCommercialShareAlike-3.0 License, which permits use, distribution and reproduction for non-commercial purposes, provided the original is properly cited and derivative works building on this content are distributed under the same license. 